\title{
New insights on organosilane oligomerization mechanisms using ESI-MS and ${ }^{29} \mathrm{Si}$ NMR
}

\author{
José Planelles-Aragó, ${ }^{* a}$ Cristian Vicent, ${ }^{* b}$ Beatriz Julián, ${ }^{a}$ Eloisa Cordoncillo ${ }^{a}$ \\ and Purificación Escribano ${ }^{a}$
}

Received (in Montpellier, France) 7th October 2008, Accepted 28th January 2009

First published as an Advance Article on the web 4th March 2009

DOI: $10.1039 / \mathbf{b 8 1 7 4 4 5 h}$

The use of electrospray ionization mass spectrometry (ESI-MS) in parallel with

${ }^{29} \mathrm{Si}$ and ${ }^{1} \mathrm{H}$ NMR to elucidate the aqueous speciation and temporal evolution of the organosilane methyldiethoxysilane (MDES) through hydrolysis and condensation processes is reported here. A suitable methodological approach for the monitoring of the oligomerization of MDES under different $\mathrm{pH}$ conditions has been developed revealing details on the particular oligomerization mechanism of this organosilane.

\section{Introduction}

The sol-gel process has proven to be a highly effective method for the synthesis of glasses, ceramics, nanocrystallites, nanoscaled amorphous materials and a large variety of multifunctional organic-inorganic hybrids under mild conditions. By introducing organic groups or polymers into the inorganic silica matrices, the properties of the sol-gel derived materials can be tailored at the molecular level according to different requirements. ${ }^{1}$ So far, a large number of silica-based sol-gel derived hybrid materials have been prepared. These hybrids are considered as innovative advanced materials, and promising applications are expected in many fields: optics, electronics, mechanics, membranes, protective coatings, catalysis, sensors and biology. ${ }^{2-4}$ Among the hybrid organic-inorganic materials, siloxane-based materials containing $\mathrm{Si}-\mathrm{H}$ functionalities are of great importance. ${ }^{5,6}$ One of the interests for this type of hybrid materials exploits the possibility of using the $\mathrm{Si}-\mathrm{H}$ groups as in situ reducing agents in the formation of $\mathrm{M} / \mathrm{SiO}_{2}$ nanocomposites $(\mathrm{M}=\mathrm{Pt}, \mathrm{Ni}, \mathrm{Cu}, \mathrm{Co})^{7}$ or divalent lanthanide doped silica based photonic materials. ${ }^{8}$ Efforts have been made to establish polymer structure-property relationships and to identify the effects that reaction conditions and monomer structure have on final polymer properties. ${ }^{9-11}$ In this sense, it has been shown that the final properties of gels are dependent on the early hydrolysis and condensation steps in forming the sol-gel. ${ }^{12-14}$ The chemistry of the sol-gel process is based on inorganic polymerization where molecular precursors (silicon alkoxides $\mathrm{Si}(\mathrm{OR})_{4}$, organically modified silicon alkoxides $\mathrm{R}_{x} \mathrm{Si}\left(\mathrm{OR}^{\prime}\right)_{4-x}(x=1,2)$ or transition metal alkoxides, $\mathrm{M}(\mathrm{OR})_{4}$, where $\mathrm{R}$ and $\mathrm{R}^{\prime}$ can be chosen from a large variety of organic groups and $\mathrm{M}$ is usually an element from groups 4 or 5) undergo hydrolysis of alkoxide groups

\footnotetext{
${ }^{a}$ Departamento de Química Inorgánica y Orgánica, Universitat Jaume I Avenida Vicente Sos Baynat s/n, E-12071 Castellón, Spain.

E-mail: jplanell@qio.uji.es,escriban@qio.uji.es,cordonci@qio.uji.es; Fax: + 34 964728214; Tel: + 34964728247

${ }^{b}$ Servicios Centrales de Instrumentación Cientifica (SCIC),

Universitat Jaume I, Avenida Vicente Sos Baynat $s / n$,

E-12071 Castellón, Spain.E-mail: barrera@sg.uji.es
}

$(-\mathrm{OR})$ and subsequent condensation reactions that lead to the formation of metal or metalloid oxo-based macromolecular networks. ${ }^{15,16}$ These processes can be illustrated in Scheme 1 for a typical silicon alkoxide (eqn (1)-(3)).

Hydrosilanes (containing hydrogen atoms attached to silicon) are exceptionally useful reagents that can be used as reducing agents in their own right, or as precursors to a series of different silicon containing compounds. With the exception of the parent silane $\mathrm{SiH}_{4}$, the reactions between water or alcohol and hydrosilanes (Scheme 1, eqn (4) and (5)) are kinetically slow. Activation to reaction normally requires base, strong acid, radical conditions or the presence of transition metal complexes, and the by-product of the reaction is hydrogen gas, which may be used to reduce several compounds. ${ }^{17}$

The oligomeric equilibria of silicon alkoxides has been studied extensively and ${ }^{29} \mathrm{Si}$ NMR spectroscopy has contributed greatly to the knowledge of aqueous speciation of silsesquioxanes (polymers or polyhedral clusters having the generic formula $\left.\left(\mathrm{RSiO}_{1.5}\right)_{n}\right)$ and silicate-based oligomers. ${ }^{14,15,18}$ The distinctive shielding of the ${ }^{29} \mathrm{Si}$ nucleus due its chemical environment allows the identification of silicate oligomers according to the chemical shift. Despite the long tradition on employing this technique for characterization purposes, some disadvantages are inherent to the ${ }^{29} \mathrm{Si}$ NMR experiments. First, owing to both the low natural abundance of ${ }^{29} \mathrm{Si}$ nuclei and its small and negative magnetogyric ratio, ${ }^{29} \mathrm{Si} \mathrm{NMR}$ experiments are quite time consuming. In addition, for quantitative measurements in

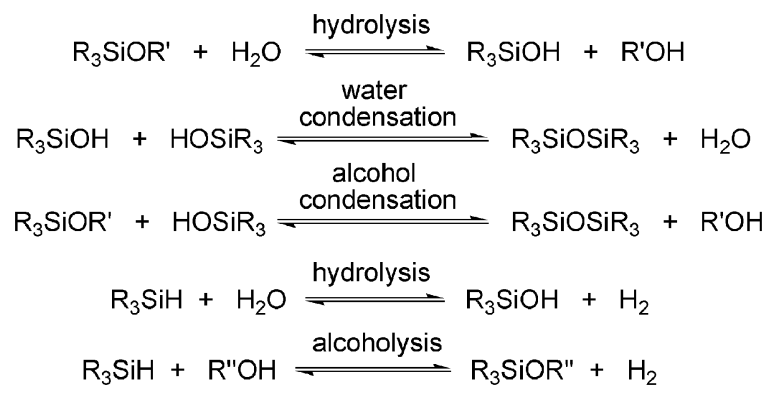

Scheme 1 Hydrolysis (and subsequent condensation) reactions of silicon alkoxides and hydrosilanes. 
systems with fast evolution, this technique is inappropriate as the use of long recycle delays is mandatory. Second, in complex systems, the nature of silicon species and the length of the oligomers are difficult to determine due to the spectral overlapping of the ${ }^{29} \mathrm{Si}$ signals, therefore providing oversimplified information or ambiguous attributions of the aqueous speciation. In this context, soft ionization mass spectrometric techniques are a promising alternative method and have recently appeared as a major breakthrough for the analysis of silicate-based or silesquioxanes oligomers. In particular, matrix-assisted lased desorption ionization (MALDI) and electrospray ionization (ESI) mass spectrometry techniques have been used to study the polymer composition as well as molecular weight information on numerous silsesquioxanes. ${ }^{19-24}$

Recently, ESI-MS have also been successfully used to investigate the aqueous speciation and monitor the temporal evolution of silicate solutions in strong basic ${ }^{25-28}$ and acid ${ }^{29}$ media. In this sense, ESI methods present some advantages in comparison to MALDI ionization techniques. ${ }^{30}$ Essentially, MALDI-MS is a inherently off-line technique in which analytes must be previously crystallized (in comparison to ESI methods where analytes are measured directly from solution) and as a result, the course of the oligomerization process is hindered. Moreover, potential problems for the analysis of low mass oligomers are present due to the matrix interference. Due to a variety of outstanding features and advantages, ESI-MS (and its tandem version ESI-MS/MS) is rapidly becoming the most suitable tool for the fast screening of intermediates directly from solution not only for silicon-containing oligomers but also, for example, for alkene polymerizations. $^{31-33}$

Herein, we report on the use of ESI mass spectrometry in parallel with ${ }^{29} \mathrm{Si}$ NMR to elucidate the aqueous speciation and temporal evolution of the organosilane methyldiethoxysilane (MDES). Although hydrolysis can occur without addition of an external catalyst, it is most rapid and complete when acid or basic conditions are employed. Additionally, the rate and the extent of hydrolysis and condensation processes are mostly influenced by the amounts of water as well as the concentration and nature of acid or base catalyst. These parameters also control the number and nature (i.e. length, cross-linking degree) of the oligomers in solution. In this work we will focus on the hydrolysis and condensation of MDES under three specific $\mathrm{pH}$ conditions as a case study. In particular MDES solutions at pH $1(\mathrm{HCl}), \mathrm{pH} 6$ (pure water) and $\mathrm{pH} 13(\mathrm{NaOH})$ have been investigated in this study using fixed MDES : EtOH : $\mathrm{H}_{2} \mathrm{O}$ ratios. Through the combined use of ${ }^{29} \mathrm{Si}$ NMR and ESI-MS techniques, a complete picture of the MDES aqueous speciation and new insights on the oligomerization mechanism process are proposed.

\section{Experimental}

\section{Sample preparation}

All reagents were obtained from commercial sources and used as received. Methyldiethoxysilane (MDES, $\left(\mathrm{CH}_{3}\right) \mathrm{HSi}\left(\mathrm{OCH}_{2} \mathrm{CH}_{3}\right)_{2}$ $97 \%$, ABCR), Millipore filtered deionized water, sodium hydroxide $(\mathrm{NaOH}$, Probus, 97\%), hydrochloric acid $(\mathrm{HCl}$, J.T. Baker, 37\%) and sodium chloride ( $\mathrm{NaCl}$, Merck, 99\%) were used. Synthesis grade absolute ethanol (EtOH, Scharlau) was dehydrated by $3 \AA$ molecular sieves before use. The general molar composition of the samples was MDES- $\mathrm{H}_{2} \mathrm{O}-\mathrm{EtOH}=$ $1: 1: 0.5$. The samples were prepared by dissolving the proper amount of MDES in ethanol and by hydrolysing the alkoxide with an aqueous solution. Different $\mathrm{pH}$ (1, 6 and 13 prepared using $\mathrm{HCl}$, deionized water and $\mathrm{NaOH}$ ) aqueous solutions were used in order to study the effect of $\mathrm{pH}$ in alkoxide hydrolysis and condensation processes. The resulting clear solutions were magnetically stirred and analysed by multinuclear ${ }^{1} \mathrm{H}$ and ${ }^{29} \mathrm{Si}\left\{{ }^{1} \mathrm{H}\right\}$ NMR and ESI mass spectrometry at different time intervals.

\section{NMR experiments}

NMR spectra were recorded on a Varian Unity Inova 500 spectrometer with a broad-band $5 \mathrm{~mm}$ probe operating at $499.785 \mathrm{MHz}$ for proton and 99.282 for ${ }^{29} \mathrm{Si}$. Spectra were referenced to external tetramethylsilane (TMS) dissolved in $\mathrm{CDCl}_{3}$ as lock solvent. ${ }^{29} \mathrm{Si}\left\{{ }^{1} \mathrm{H}\right\}$ NMR spectra of the reactions at $\mathrm{pH}=1$ and 6 were obtained using the INEPT pulse sequence optimised for a coupling constant $J=237 \mathrm{~Hz}$ (typical ${ }^{1} J_{\mathrm{Si}-\mathrm{H}}$ values for MDES and its oligomers). ${ }^{5}$ This experiment allows the transfer of the abundant high- $\gamma$ protons to the rare low- $\gamma{ }^{29} \mathrm{Si}$ nuclei through the scalar spin-spin coupling, and significantly reduce the accumulation time of the spectra. Moreover, the high value of the ${ }^{1} J_{\mathrm{Si}-\mathrm{H}}$ coupling constant (typically around $237 \mathrm{~Hz}$ ) further reduces losses of signals due to longitudinal relaxation processes and typical INEPT ${ }^{29} \mathrm{Si}\left\{{ }^{1} \mathrm{H}\right\}$ NMR spectra shown below comprise 16 scans. ${ }^{29} \mathrm{Si}\left\{{ }^{1} \mathrm{H}\right\}$ NMR spectra of the reaction at $\mathrm{pH}=13$ were obtained using the INEPT pulse sequence optimised for a coupling constant $J=9 \mathrm{~Hz}$ (typical ${ }^{2} J_{\mathrm{Si}-\mathrm{CH}_{3}}$ values in the $\mathrm{Si}-\mathrm{CH}_{3}$ groups and its oligomers) and typically 512 scans were acquired. In this case, monitoring the reaction using INEPT ${ }^{29} \mathrm{Si}\left\{{ }^{1} \mathrm{H}\right\}$ NMR (optimised for ${ }^{1} J_{\mathrm{Si}-\mathrm{H}}=237 \mathrm{~Hz}$ ) resulted in NMR silent spectra in agreement with the immediate $\mathrm{Si}-\mathrm{H}$ bond cleavage under basic conditions. ${ }^{29} \mathrm{Si}$ NMR chemical shifts assignment were carried out following the usual $\mathrm{X}_{x y}$ notation, where $\mathrm{X}$ can be $\mathrm{D}$ for difunctional silicon species $\left(\mathrm{MeHSiO}_{2}-\right)$ and $\mathrm{T}$ for trifunctional silicon species $\left(\mathrm{MeSiO}_{3}-\right)$, the $x$ subindex denotes the number of $\mathrm{Si}-\mathrm{O}-\mathrm{Si}$ oxo bridges and $y$ subindex the number of silanol groups.

\section{Electrospray ionization (ESI) mass spectrometry}

A Quattro LC (quadrupole-hexapole-quadrupole) mass spectrometer with an orthogonal Z-spray electrospray interface (Waters, Manchester, UK) was used. The temperature of the source block was $100{ }^{\circ} \mathrm{C}$ and the temperature of the interface was varied from 80 to $200{ }^{\circ} \mathrm{C}$. A capillary voltage of 3.3 and $3.5 \mathrm{kV}$ were used in the negative and positive scan mode, respectively. The drying gas as well as nebulizing gas was nitrogen at flow rates of 400 and $80 \mathrm{~L} \mathrm{~h}^{-1}$, respectively. Likewise, sample solutions identical to that used for NMR measurements were prepared for the ESI-MS analysis and were diluted with ethanol to the appropriate concentration. Different ESI conditions were used to evaluate the influence of 
the ionization process on the identity of the species present in solution. In particular, the effect of the scan mode polarity, sampling cone voltage sample concentration and the presence of additives in the solvent were investigated (further details are given below).

\section{Results and discussion}

The study of the aqueous speciation of MDES was initiated as a means of determining the identity of the silicon species and evaluating their temporal evolution due to the simultaneous hydrolysis and condensation processes. As described previously, ${ }^{15}$ such processes (hydrolysis and condensation) are strongly influenced by the relative amount of $\mathrm{EtOH}: \mathrm{H}_{2} \mathrm{O}$ : MDES as well as $\mathrm{pH}$. In order to restrict experimental variables we will focus on specific solvent compositions covering the whole $\mathrm{pH}$ range (as a case of study at $\mathrm{pH}=1,6$ and 13) at which the temporal evolution can be monitored in a reasonably time scale. The combined ${ }^{29} \mathrm{Si}\left\{{ }^{1} \mathrm{H}\right\}$ NMR and ESI-MS experimental methodology presented, however, can be regarded as a general method to investigate the MDES aqueous speciation and therefore can be extended to other initial compositions or other organically modified silanes. Herein, we first address the issue of the most convenient ESI conditions to unravel the aqueous speciation of the alkoxysilane MDES.

\section{Methodological aspects for MDES characterization using ESI mass spectrometry}

The ESI technique is amongst the less intrusive mass spectrometric ionization techniques; however this ionization process may still induce fragmentation or rearrangement processes as well as solvation of the target compound. Hence, careful setup of the experimental conditions (sample concentration, scan mode polarity or presence of additives) is required in order to find the analytical conditions leading to spectra that most closely resemble the speciation chemistry in solution. For example, the temporal evolution of silicate-based oligomers has been recently reported using simultaneously ${ }^{29} \mathrm{Si}\left\{{ }^{1} \mathrm{H}\right\}$ NMR and ESI-MS techniques. ${ }^{26,27,34}$ A detailed investigation of the experimental setup for the ESI-MS analysis in these systems has also been conducted aimed at determining the best suited ESI ion sources/designs as well as identifying potential gas-phase reactions that can disturb the identification of species present in solution. ${ }^{35}$
In order to validate whether ESI mass spectrometry may directly transfer MDES or its oligomers from solution to the gas-phase, simultaneous ${ }^{29} \mathrm{Si}\left\{{ }^{1} \mathrm{H}\right\}$ NMR and ESI-MS control experiments are carried out. For this purpose, an ethanolic MDES solution (see Table 1) is first analysed by ${ }^{29} \mathrm{Si}\left\{{ }^{1} \mathrm{H}\right\}$ NMR revealing a main signal ascribed to the MDES species (signal at $-16.4 \mathrm{ppm}$ ) together with the simplest $(\mathrm{OEt})\left(\mathrm{CH}_{3}\right)(\mathrm{H}) \mathrm{Si}-\mathrm{O}-\mathrm{Si}(\mathrm{H})\left(\mathrm{CH}_{3}\right)(\mathrm{OEt})$ oligomer (signal at $-25.2 \mathrm{ppm}$ ) originated from the hydrolysis and condensation of the precursor with traces of water from the solvent (see Fig. 1(a)). We choose this solution as a control experiment because of the presence of only two well-identified species in solution. Hence, the ESI-MS analysis of this solution should be diagnostic as to whether the ESI process simply transfers species present in solution to the gas phase or otherwise promotes self-aggregation, oligomerization or hydrolysis during the ionization process.

We have undertaken a series of ESI-MS experiments on the control sample to evaluate the effect of: (i) scan mode polarity (+ or -); (ii) sampling cone voltage, (iii) different sample concentration, and (iv) inlet temperature. In general, ESI-MS analysis can be conducted either in the positive and negative scan mode where the presence of $\mathrm{Na}^{+}$and $\mathrm{Cl}^{-}$adducts represents the most favourable ionization mechanism. In all cases, the addition of traces of $\mathrm{NaCl}$ in the sample aliquot results in improved signal-to-noise ratio for all species detected while the chemical speciation remains unchanged. $\mathrm{NaCl}$ addition was carried out just before ESI-MS analysis in order to avoid potential effects of this salt on the chemical speciation. ${ }^{36-38}$ Table 1 collects the species detected by ESI-MS under different experimental conditions.

ESI mass spectra in the positive scan mode is dominated by the presence of sodium $[\mathrm{MDES}+\mathrm{Na}]^{+}$and $\left[(\mathrm{OEt})\left(\mathrm{CH}_{3}\right)(\mathrm{H}) \mathrm{Si}-\right.$ $\left.\mathrm{O}-\mathrm{Si}(\mathrm{H})\left(\mathrm{CH}_{3}\right)(\mathrm{OEt})+\mathrm{Na}\right]^{+}$adducts (entry 1$)$. Conversely, the species detected by $\mathrm{ESI}(-)$-MS are partially hydrolyzed alkoxysilanes, namely $\left[\left(\mathrm{CH}_{3}\right)(\mathrm{H}) \mathrm{Si}(\mathrm{OH})(\mathrm{OEt})+\mathrm{Cl}\right]^{-}$and $\left[\left(\mathrm{CH}_{3}\right)(\mathrm{H}) \mathrm{Si}(\mathrm{OH})_{2}+\mathrm{Cl}\right]^{-}$monomers together with the corresponding oligomers (entry 2). Thus, ESI(+)-MS results are in good agreement with those obtained in ${ }^{29} \mathrm{Si}\left\{{ }^{1} \mathrm{H}\right\}$ NMR experiments for the control MDES solution. In both, only non-hydrolyzed species are detected (Fig. 1). As a result, despite both $(+$ and -$)$ scanning modes providing complementary information regarding the extent of oligomerization, the identification of the species present in solution

Table 1 Species detected by ESI-MS under different experimental conditions for the control MDES solution

\section{Experimental conditions}

Scan polarity

(1) $\operatorname{ESI}(+)-\mathrm{MS}$

(2) ESI(-)-MS

Cone voltage

(3) below $U_{\mathrm{c}}=20 \mathrm{~V}$

(4) above $U_{\mathrm{c}}=20 \mathrm{~V}$

Sample concentration

(5) $1 \times 10^{-4} \mathrm{M}$

(6) $1 \times 10^{-3} \mathrm{M}$

(7) $1 \times 10^{-2} \mathrm{M}$
Species detected

$[\mathrm{MDES}+\mathrm{Na}]^{+},\left[(\mathrm{OEt})_{2}\left(\mathrm{CH}_{3}\right)_{2}(\mathrm{H})_{2} \mathrm{Si}_{2} \mathrm{O}+\mathrm{Na}\right]^{+}$

$\left[(\mathrm{OH})(\mathrm{OEt})\left(\mathrm{CH}_{3}\right)(\mathrm{H}) \mathrm{Si}+\mathrm{Cl}\right]^{-},\left[(\mathrm{OH})_{2}\left(\mathrm{CH}_{3}\right)(\mathrm{H}) \mathrm{Si}+\mathrm{Cl}\right]^{-}$,

$\left[(\mathrm{OH})_{n}(\mathrm{OEt})_{2-n}\left(\mathrm{CH}_{3}\right)_{2}(\mathrm{H})_{2} \mathrm{Si}_{2} \mathrm{O}+\mathrm{Cl}\right]^{-}(n=0,1,2)$

Identical to entry 1

$[\mathrm{MDES}+\mathrm{Na}]^{+},[\mathrm{MDES}-\mathrm{EtOH}+\mathrm{Na}]^{+}$

$\left[(\mathrm{OEt})_{2}\left(\mathrm{CH}_{3}\right)_{2}(\mathrm{H})_{2} \mathrm{Si}_{2} \mathrm{O}+\mathrm{Na}\right]^{+},\left[(\mathrm{OEt})_{2}\left(\mathrm{CH}_{3}\right)_{2}(\mathrm{H})_{2} \mathrm{Si}_{2} \mathrm{O}-\mathrm{EtOH}+\mathrm{Na}\right]^{+}$

$[\mathrm{MDES}+\mathrm{Na}]^{+},\left[(\mathrm{OEt})_{2}\left(\mathrm{CH}_{3}\right)_{2}(\mathrm{H})_{2} \mathrm{Si}_{2} \mathrm{O}+\mathrm{Na}\right]^{+}$

$[\mathrm{MDES}+\mathrm{Na}]^{+},[2 \mathrm{MDES}+\mathrm{Na}]^{+},\left[(\mathrm{OEt})_{2}\left(\mathrm{CH}_{3}\right)_{2}(\mathrm{H})_{2} \mathrm{Si}_{2} \mathrm{O}+\mathrm{Na}\right]^{+}$

$[\mathrm{MDES}+\mathrm{Na}]^{+},[2 \mathrm{MDES}+\mathrm{Na}]^{+},\left[(\mathrm{OEt})_{2}\left(\mathrm{CH}_{3}\right)_{2}(\mathrm{H})_{2} \mathrm{Si}_{2} \mathrm{O}+\mathrm{Na}\right]^{+}$ 


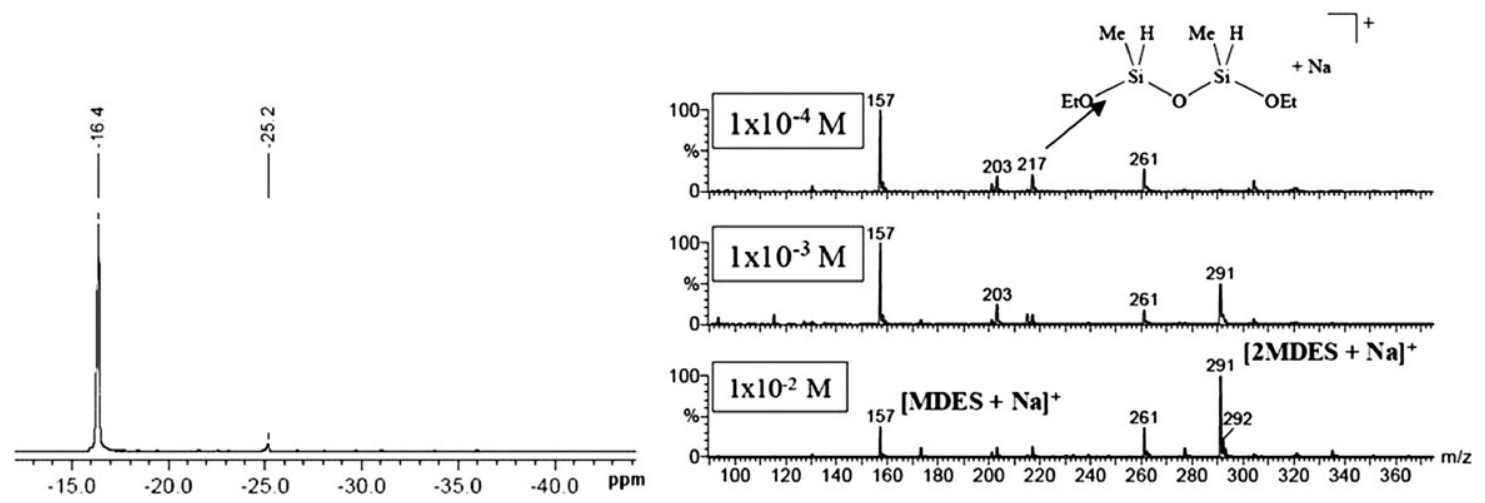

Fig. 1 (a) INEPT ${ }^{29} \mathrm{Si}\left\{{ }^{1} \mathrm{H}\right\}$ NMR spectrum and (b) ESI(+) mass spectra of an ethanolic MDES solution at different concentrations.

as alkaline adducts in the $\operatorname{ESI}(+)-\mathrm{MS}$, free from partial hydrolysis processes during the ionization, is therefore more suited to study the aqueous speciation of MDES. We hypothesize that the formation of robust alkaline adducts involving oxygen atoms from the ethoxy group prevents the species from hydrolysis during the ionization process.

One of the most decisive parameters affecting the ionization conditions is the cone voltage $U_{\mathrm{c}}$, which determines the amount of collisional activation of the originally formed ions in the differential pumping system of an ESI source. Optimal observation of the desired species was typically observed at low sampling cone voltages, $U_{\mathrm{c}}=20 \mathrm{~V}$ (entry 3 ) whereas at higher cone voltages values, extensive fragmentation (mainly due to ethanol losses) accompanied by signal reduction is observed (entry 4). ESI $(+)$ mass spectra of ethanolic solutions of MDES were also recorded at different concentrations ranging from $10^{-2}-10^{-5} \mathrm{M}$ (see Fig. 1(b)). The use of sample solutions at concentrations above $10^{-3} \mathrm{M}$ results in more crowded ESI mass spectra due to cluster aggregation processes (signals labelled as [2MDES $+\mathrm{Na}]^{+}$). ESI mass analysis of highly concentrated samples is typically dominated by cluster aggregates. $^{39}$ As the concentration is decreased, only the presence of sodium $[\mathrm{MDES}+\mathrm{Na}]^{+}$and $\left[(\mathrm{OEt})\left(\mathrm{CH}_{3}\right)(\mathrm{H}) \mathrm{Si}-\right.$ $\left.\mathrm{O}-\mathrm{Si}(\mathrm{H})\left(\mathrm{CH}_{3}\right)(\mathrm{OEt})+\mathrm{Na}\right]^{+}$adducts are observed (see entries 5, 6 and 7). The simplest oligomer $\left[(\mathrm{OEt})\left(\mathrm{CH}_{3}\right)(\mathrm{H}) \mathrm{Si}-\right.$ $\left.\mathrm{O}-\mathrm{Si}(\mathrm{H})\left(\mathrm{CH}_{3}\right)(\mathrm{OEt})+\mathrm{Na}\right]^{+}(m / z=217)$ is not formed to a significant extent, thus its concentration remains low and consequently no cluster aggregation is observed. It is important to bear in mind this experimental evidence in order to determine the most suitable concentration for the MDES analysis upon hydrolysis/condensation. That is, hydrolysis/ condensation of MDES will result in an assortment of oligomers with lower concentrations to that of the initial MDES and consequently higher concentrations (based on the initial MDES amount) are required. In order to evaluate the plausible effect of inlet temperature of the mass spectrometer, ESI mass spectra of MDES solutions were recorded at different interface temperatures ranging from 80 to $200{ }^{\circ} \mathrm{C}$. In the present case, minor differences were observed, thus suggesting that inlet temperature does not significantly affect the identity of species detected in the gas-phase.

In summary, our results indicate that a convenient methodological approach for the monitoring of the temporal evolution of MDES consists of the combined ${ }^{1} \mathrm{H},{ }^{29} \mathrm{Si}\left\{{ }^{1} \mathrm{H}\right\}$
NMR and ESI(+)-MS analysis. Through this multilateral approach we have undertaken a detailed analysis of the aqueous speciation of MDES under three different $\mathrm{pH}$ values.

\section{Aqueous speciation at $\mathrm{pH}=6$ and $\mathrm{pH}=1$}

The temporal evolution of MDES hydrolysis/condensation was monitored by ${ }^{1} \mathrm{H},{ }^{29} \mathrm{Si}\left\{{ }^{1} \mathrm{H}\right\}$ NMR and ESI-MS techniques at two specific $\mathrm{pH}$ values $(\mathrm{pH}=6$ and 1) under fixed MDES- $\mathrm{H}_{2} \mathrm{O}-\mathrm{EtOH}(1: 1: 0.5)$ experimental conditions. Under these conditions, the hydrolysis reaction is performed with under-stoichiometric amounts of water (for stoichiometric conditions the MDES : $\mathrm{H}_{2} \mathrm{O}$ ratio would be $1: 2$, since each molecule of MDES possesses two hydrolysable OEt groups) and condensation commences before hydrolysis is complete. Thus, condensation between incompletely hydrolyzed species is expected to occur and, because the alcohol-producing condensation rate is lower than the water-producing condensation rate, the pattern of condensation will reflect the pattern of hydrolysis. ${ }^{15}$ Except for the distinctive temporal evolution observed at both $\mathrm{pH}$ values, the identity of the detected intermediates is quite similar and is described together herein. The ${ }^{1} \mathrm{H}$ NMR analysis of the reaction at $\mathrm{pH}=1$ and 6 gave little information about the reaction intermediates, but allowed us to confirm that the relative intensities of the methyl and hydride groups in the MDES (or its oligomers) remains unchanged. This result indicates the inertness of the $\mathrm{Si}-\mathrm{H}$ and $\mathrm{Si}-\mathrm{CH}_{3}$ functional groups under acidic and neutral media.

The ${ }^{29} \mathrm{Si}\left\{{ }^{1} \mathrm{H}\right\}$ NMR spectra of a mixture of MDES- $\mathrm{H}_{2} \mathrm{O}-\mathrm{EtOH}$ ( $1: 1: 0.5)$ (measured $\mathrm{pH}=6$ ) is recorded at different time intervals. In general, the temporal evolution followed by ${ }^{29} \mathrm{Si}\left\{{ }^{1} \mathrm{H}\right\}$ NMR spectroscopy is fully consistent with previously reported data at closely related conditions and are briefly addressed here. ${ }^{5,6}$ In the first stages of the reaction (typically at reaction times below $30 \mathrm{~min}$ ), the signal due to the starting $\operatorname{MDES}\left(\mathrm{D}_{00}, \mathrm{MeHSi}(\mathrm{OEt})_{2}\right.$ at $\left.-16.4 \mathrm{ppm}\right)$ shows a smooth diminution with the concomitant appearance of signals centered at $-25.2 \mathrm{ppm}\left(\mathrm{D}_{10}\right.$ units, $\mathrm{MeHSi}(\mathrm{OEt}) \mathrm{O}-$ ) and $-34.3 \mathrm{ppm}\left(\mathrm{D}_{20}\right.$ units, $\left.\mathrm{MeHSiO}_{2}-\right)$ in agreement with the advance of condensation. As the reaction advances, the intensity changes of the signals agree with the smooth evolution of species from $-16.4 \rightarrow-25.2 \rightarrow-34.3 \mathrm{ppm}$ so that after $20 \mathrm{~h}$, the peak at $-34 \mathrm{ppm}$ is the most prominent peak in the ${ }^{29} \mathrm{Si}$ NMR spectrum and the reaction reaches a stationary 


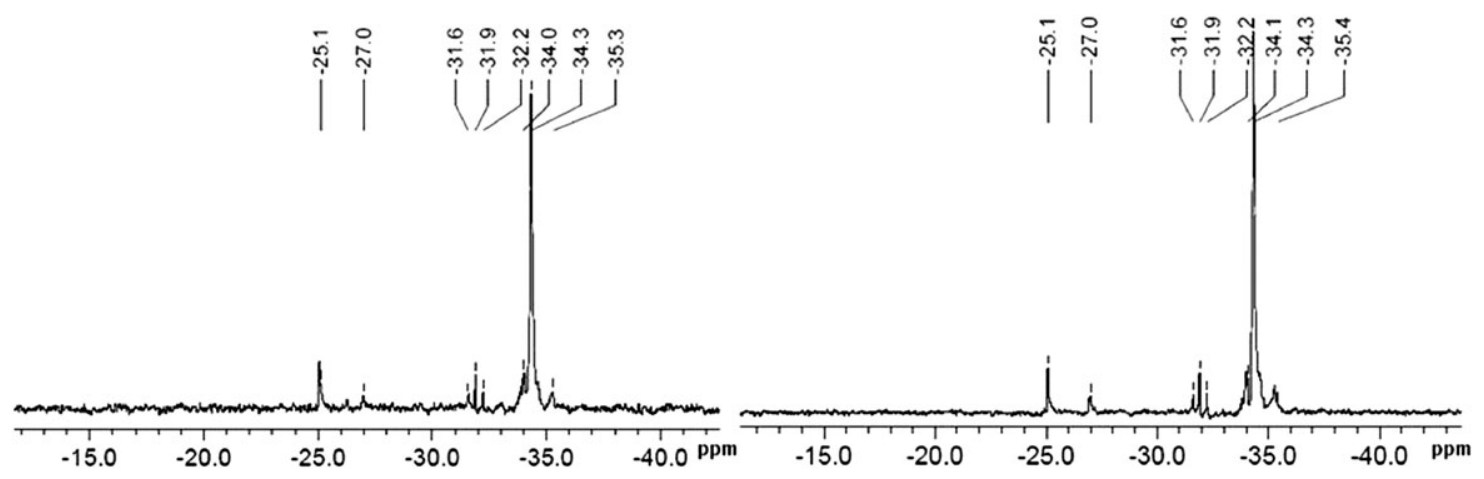

Fig. 2 INEPT ${ }^{29} \mathrm{Si}\left\{{ }^{1} \mathrm{H}\right\}$ NMR spectrum of MDES solution at (a) $\mathrm{pH}=6$ after $20 \mathrm{~h}$ and (b) $\mathrm{pH}=1$ after $1 \mathrm{~h}$.

stage. The ${ }^{29} \mathrm{Si}\left\{{ }^{1} \mathrm{H}\right\}$ NMR spectra recorded after the stationary state is reached for samples at $\mathrm{pH}=6(20 \mathrm{~h})$ and $1(1 \mathrm{~h})$ are shown in Fig. 2.

When hydrolysis of MDES solution is performed in acidic media, the observed species are closely related to that described above using pure distilled water as judged by ${ }^{29} \mathrm{Si}\left\{{ }^{1} \mathrm{H}\right\}$ NMR analysis. However, the appearance of the new signals is faster with respect to that observed in neutral media, in agreement with the expected faster hydrolysis rate under acidic conditions. For example MDES consumption is immediately observed and the reaction reaches the stationary state in a few minutes. The high hydrolysis rate is characteristic of acid catalysis but, in this case, the nucleophilic attack of the water molecules to silane units is even more favored by the small steric effect of the H-substituent. ${ }^{6}$

Partial hydrolysis can be reasonably expected to occur in the presence of water either in neutral and acidic media, thus resulting in silanol groups that appear at different chemical shifts with relatively low abundance. This is illustrated in the ${ }^{29} \mathrm{Si}\left\{{ }^{1} \mathrm{H}\right\}$ NMR spectra (see Fig. 2) where a set of signals centered around $-27,-32$ and -33 ppm are observed. As anticipated by several authors, a definitive assignment of all ${ }^{29} \mathrm{Si}\left\{{ }^{1} \mathrm{H}\right\}$ NMR signals is not trivial since chemical shifts are very sensitive to the medium effects as well as to the neighbouring silicon environments. ${ }^{40}$ For example signals centered at $-27 \mathrm{ppm}$ are tentatively attributed to silicon atoms in $\mathrm{D}_{11}-\mathrm{D}_{10}, \mathrm{D}_{10^{-}}-\mathrm{D}_{20^{-}}, \mathrm{D}_{11^{-}}-\mathrm{D}_{20^{-}}$environments and the second set of signals between -31 and -33 are characteristic of $\mathrm{D}_{20}$ units linked to different silica units $\mathrm{D}_{10}-\mathrm{D}_{20}-\mathrm{D}_{10}$, $\mathrm{D}_{10}-\mathrm{D}_{20}-\mathrm{D}_{11}$ etc. (note that the most intense signal located at $-34.3 \mathrm{ppm}$ is assigned to $\mathrm{D}_{20}-\mathrm{D}_{20}-\mathrm{D}_{20}$ ). It is important to note that ${ }^{29} \mathrm{Si}$ NMR spectra obtained after the steady state of the reaction is reached appear quite simplified in both cases $(\mathrm{pH}=1$ and 6$)$ which can be attributed to the inherently similar environment of the dominant $\mathrm{D}_{20}-\mathrm{D}_{20}-\mathrm{D}_{20}$ silicon atoms $(-34.3 \mathrm{ppm})$ present in the oligomers. Moreover, this latter signal is relatively narrow which indicates a high regularity of the oligomers formed, as expected for difunctionalized silanes for which linear oligomers are likely formed.

Despite these results put forward that ${ }^{29} \mathrm{Si}\left\{{ }^{1} \mathrm{H}\right\}$ NMR analysis furnishes useful information at determining the extent of the condensation, limited or ambiguous information on the molecular organization of the oligomers formed is obtained. To obtain further insights on the aqueous speciation, ESI-MS analysis were carried out in parallel. Different aliquots were taken from the reaction mixture, diluted with ethanol, doped with $\mathrm{NaCl}$, and analyzed by ESI-MS. The species detected by ESI-MS could be monitored either the positive and negative scan mode as sodium or chloride adducts, thus suggesting that species present in solution are neutral. Remarkably, the distribution of oligomers detected by ESI $(+)$-MS or ESI(-)-MS is comparable; however, the presence of fully or partially hydrolyzed species in the $\operatorname{ESI}(-)$ mass spectra is dominant whereas ESI $(+)$ mass spectra display partially and non-hydrolyzed species. These results are reminiscent to that described above for the control experiment and suggest that $\operatorname{ESI}(+)-\mathrm{MS}$ analysis, is more suited to identify species present in solution. The use of higher concentrations resulted in unwanted cluster aggregation processes during electrospray so that samples were diluted with ethanol in the $10^{-1}-10^{-3} \mathrm{M}$ (based on the initial amount of MDES) range. It is important to note that minor differences in the $\operatorname{ESI}(+)$-MS were observed as the degree of dilution varies in the $10^{-1}-10^{-3} \mathrm{M}$ range, thus suggesting the absence of dynamic behaviour of the oligomers with respect to the hydrolysis of the $\mathrm{Si}-\mathrm{O}-\mathrm{Si}$ groups. In addition, the relative intensity of oligomers with silanol groups slightly decrease upon dilution with respect to the non-hydrolyzed oligomers, thus indicating that the high ethanol content during dilution does not promote unwanted $\mathrm{Si}-\mathrm{OH}$ to $\mathrm{Si}-\mathrm{OEt}$ transformation to any significant extent. We also investigate MDES speciation at different inlet temperatures ranging from 80 to $200{ }^{\circ} \mathrm{C}$. It is well known that the moderate temperatures (typically above $100{ }^{\circ} \mathrm{C}$ are required for desolvation) experienced during the electrospray process are likely to speed up the monitored reactions by ESI-MS. ${ }^{41}$ In the present case, only minor differences are observed in the ESI mass spectra upon varying the inlet temperature. In particular, the extent of oligomerization is not affected to any significant extent by the use of different desolvation temperatures as the envelope defined by the oligomer distribution remains largely unchanged. Further support to the absence of accelerated oligomerization as a consequence of the ESI process is given by the fact that the disappearance of both monomers and dimers (which are clearly identified by ${ }^{29} \mathrm{Si} \mathrm{NMR}$ ) occurs at identical time intervals regardless of the technique, namely ${ }^{29} \mathrm{Si}$ NMR or ESI-MS, employed. The ESI mass spectra of a mixture of MDES- $\mathrm{H}_{2} \mathrm{O}-\mathrm{EtOH}(1: 1: 0.5)$ at different time intervals are shown in Fig. 3. 


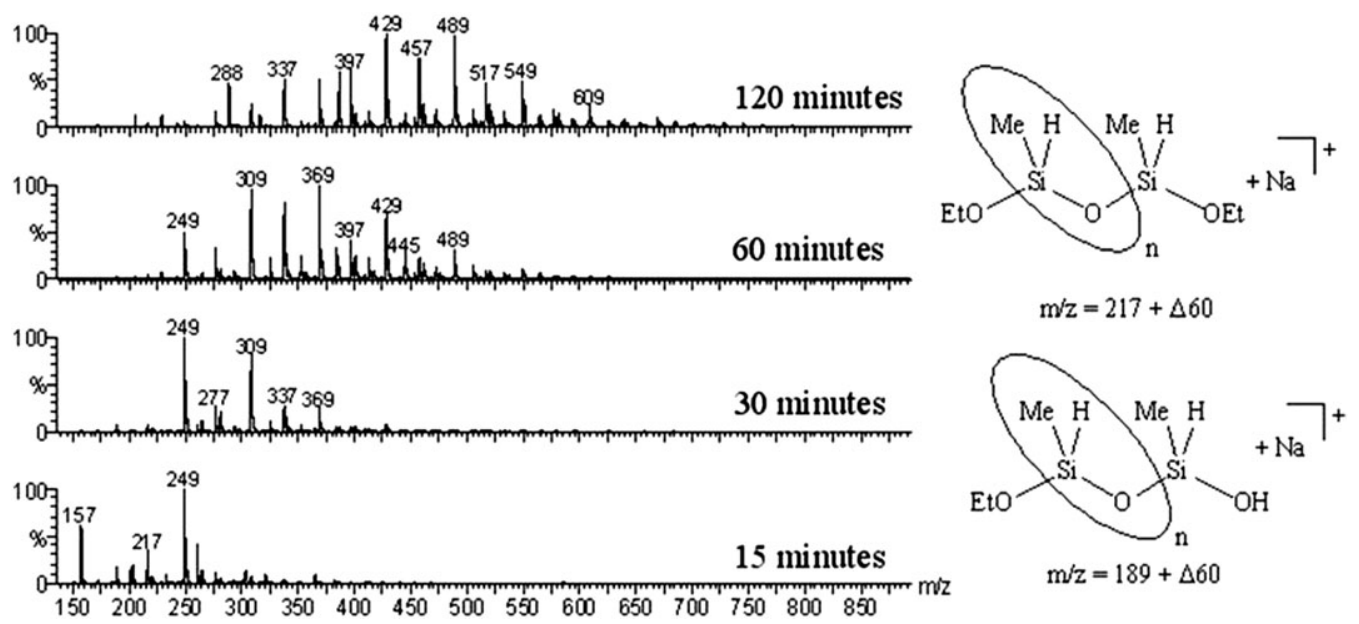

Fig. $3 \mathrm{ESI}(+)$ mass spectra illustrating the temporal evolution of MDES oligomers at $\mathrm{pH}=6$.

In agreement with the ${ }^{29} \mathrm{Si}\left\{{ }^{1} \mathrm{H}\right\}$ NMR measurements described above, the ESI $(+)$-MS spectra for the reaction of MDES at $\mathrm{pH}=6$ show the presence of unreacted MDES (peak at $m / z=157$ ) at the initial stages of the reaction together with minor signals due to the partially hydrolyzed MDES, namely $\left[(\mathrm{OEt})(\mathrm{OH})\left(\mathrm{CH}_{3}\right)(\mathrm{H}) \mathrm{Si}+\mathrm{Na}\right]^{+}(m / z=129)$. After $c a .30 \mathrm{~min}$, initial MDES is consumed and as the reaction advances two series of signals starting at $m / z=189$ and $m / z=217$ are observed that formally correspond to linear oligomers with a " $\mathrm{SiO}(\mathrm{H})\left(\mathrm{CH}_{3}\right)$ " repeating unit $(\Delta m=60)$. Both series are assigned to the partially hydrolyzed oligomers at one end-group (that starting at $m / z=189$ ) and the non-hydrolyzed oligomers (that starting at $m / z=217$ ). It is remarkable that in the present case, $\operatorname{ESI}(+)$-MS analysis allows to clearly distinguish between hydrolyzed silanol groups and non-hydrolyzed groups, a problem not amenable by NMR techniques due to the low overall contribution of silicon atoms possessing these functional groups.

For the acid catalyzed reaction, the ESI $(+)$-MS spectra are very much alike to those observed for the reaction at neutral $\mathrm{pH}$ values except for the temporal formation of oligomers. The $\operatorname{ESI}(+)$-MS spectra at different time intervals for the reaction of MDES at $\mathrm{pH}=1$ (see Fig. 4) show the presence of two series of species attributed to the fully hydrolyzed oligomers (that starting at $m / z=161$ ) and the partially hydrolyzed oligomers (that starting at $m / z=189$ ). Like MDES oligomerization at $\mathrm{pH}=6$, the distribution of the peaks show a separation $\Delta m=60$ that formally corresponds to a " $\mathrm{SiO}(\mathrm{H})\left(\mathrm{CH}_{3}\right)$ " repeating unit.

An inspection of the temporal evolution of these series reveals some insights on the intimate mechanism of oligomerization. As expected, it is clearly observed that MDES oligomers formed under acid-catalized conditions present a higher extent of hydrolysis to that observed for the MDES solution at neutral $\mathrm{pH}$ values and consequently, the extent of condensation is favoured for the acid catalyzed reaction. This is illustrated in the envelope defined by the ESI-MS detected oligomeric ions at neutral $\mathrm{pH}$ values (envelope centered in the $m / z=200-300$ range), whereas this envelope is shifted to the $m / z=300-600$ for the acid-catalyzed reaction after $1 \mathrm{~h}$.

It should be pointed out that the shape of this envelope is rather symmetric for the sample at $\mathrm{pH}=6$ which may be ascribed to an oligomerization mechanism that consists of stepwise condensation of monomers with larger oligomers. However as can be inferred from Fig. 3, monomeric species are not detected after $c a .30 \mathrm{~min}$, thus this sequence of condensation requires both depolymerization and the availability of monomers which are in solution equilibrium with the oligomeric species.
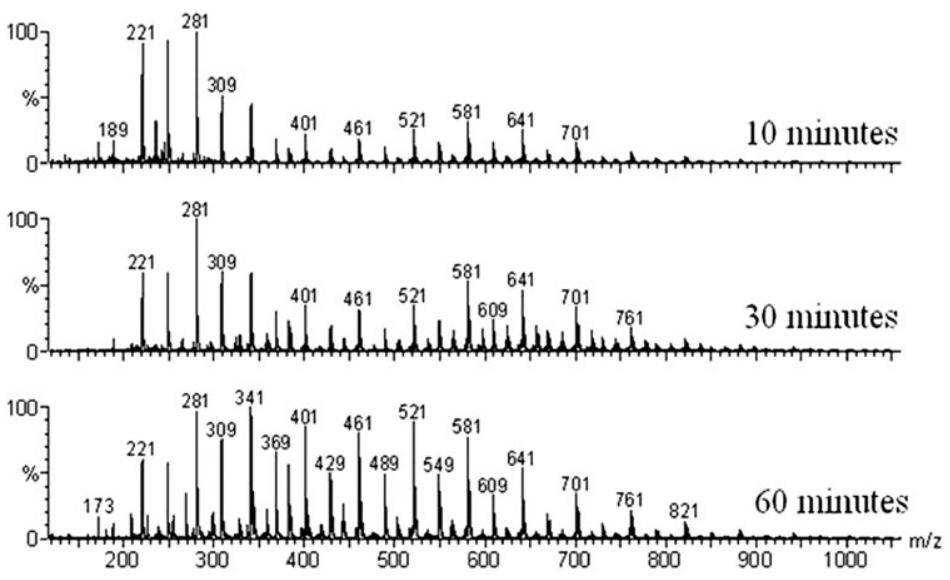

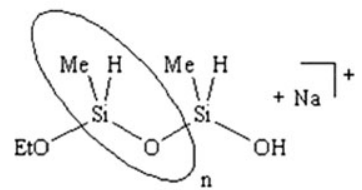

$\mathrm{m} / \mathrm{z}=189+\Delta 60$

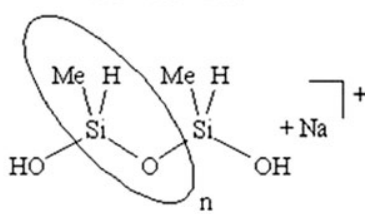

$\mathrm{m} / \mathrm{z}=161+\Delta 60$

Fig. $4 \mathrm{ESI}(+)$ mass spectra illustrating the temporal evolution of MDES oligomers at $\mathrm{pH}=1$. 
In this system at near steady-state conditions, it can be assumed that each step, namely hydrolysis (or its reverse reaction), condensation and depolymerization, possess different rate constants, but they must all have the same rate. Since the rate of each process is the rate constant multiplied by one or more concentrations, the most abundant species in the ESI mass spectrum will be those species prior to the reaction for which the rate constant is smallest. ${ }^{32}$ Hence, the absence of monomers at $\mathrm{pH}=6$ can be interpreted in terms of very slow depolymerization reactions relative to the faster monomer to oligomer condensation. A similar mechanism has also been proposed for the oligomerization based on the depolymerization and monomer to oligomer condensation for the TEOS (tetraethoxysilane). ${ }^{42}$ With respect to the acid-catalyzed sample, its envelope presents some deviations from the regular sine bell shape, a fact that could be attributed to an oligomerization mechanism that involves stepwise monomer condensation along with condensation of larger oligomers.

It is also observed that the presence of partially hydrolyzed oligomers in the early stages of the reaction is dominant in neutral media whereas their relative intensities with respect to the non-hydrolyzed species decrease as the mixture approximates to the steady state. An identical trend is observed for the acid-catalyzed reaction. For example in the sample at $\mathrm{pH}=6$, the series of ions starting at 217 increase relative to that starting at 189 and for the sample at $\mathrm{pH}=1$, the series starting at 189 increase relative to that at 161 . These results indicate that $\mathrm{Si}-\mathrm{OH}$ groups are mainly accumulated in the early stages of the reaction, and consequently the relative rate of $\mathrm{Si}-\mathrm{OEt}$ hydrolysis $v s$. condensation or $\mathrm{Si}-\mathrm{OH}$ ethanolysis is high, whereas as the reaction advances this ratio tends to equilibrate. Finally, it must be noted that despite the putative presence of cyclic oligomers, they are not observed in the $\operatorname{ESI}(+)$ mass spectra, likely due to the presence of non-hydrolyzed OEt groups, that effectively reduce the functionality, promoting the formation of more weakly branched structures. ${ }^{15}$

\section{Aqueous speciation at $\mathrm{pH}=13$}

When MDES solution is hydrolyzed under basic conditions, $\mathrm{H}_{2}$ gas arising from $\mathrm{Si}-\mathrm{H}$ bonds cleavage is immediately released. ${ }^{1} \mathrm{H}$ NMR reaction monitoring of the MDES at
$\mathrm{pH}=13$ also provides limited insight about the reaction intermediates formed, but revealed the immediate disappearance of the hydride groups. Attempts to monitor the temporal evolution of the system by ${ }^{29} \mathrm{Si}\left\{{ }^{1} \mathrm{H}\right\}$ NMR spectroscopy were unsuccessful due to the rapid reaction evolution and the long acquisition times required. The immediate sampling of the reaction mixture reveals the absence of MDES and new signals centered around $-41.5,-50.4,-59.0$ and -64.2 to $-67.2 \mathrm{ppm}$ can be inferred from ${ }^{29} \mathrm{Si}\left\{{ }^{1} \mathrm{H}\right\}$ NMR spectra whose relative intensities varies during the acquisition. These chemical shifts are characteristic of silicon atoms possessing $\mathrm{T}_{00}$ (at $-41.5 \mathrm{ppm}$ ), $\mathrm{T}_{10}$ (signals at $-50.4 \mathrm{ppm}$ ), $\mathrm{T}_{20}$ (signals at $-59.0 \mathrm{ppm}$ ) and $\mathrm{T}_{30}$ (signals at in the $-64.2-67.2 \mathrm{ppm}$ range) environments. For longer reaction times ( $c a .5 \mathrm{~h}$ ), the presence of only two broad signals centered around -64 and $67 \mathrm{ppm}$ is observed (see Fig. 5) that suggest the formation of either linear and branched oligomers. These ${ }^{29} \mathrm{Si}\left\{{ }^{1} \mathrm{H}\right\}$ NMR spectra are very much alike to that reported for the hydrolysis/condensation of methyltriethoxysilane (MTES) under acid conditions, an expected observation since MDES $\mathrm{Si}-\mathrm{H}$ bond cleavage formally leads to MTES. $^{43}$ The $\operatorname{ESI}(+)$-MS spectra at different time intervals for the reaction of MDES at $\mathrm{pH}=13$ are shown in Fig. 5 along with the ${ }^{29} \mathrm{Si}\left\{{ }^{1} \mathrm{H}\right\}$ NMR spectra.

In agreement with the ${ }^{29} \mathrm{Si}\left\{{ }^{1} \mathrm{H}\right\}$ NMR measurements described above, the $\mathrm{ESI}(+)$-MS spectra for the reaction of MDES at $\mathrm{pH}=13$ show the immediate absence of MDES and the appearance of several series of oligomers as the reaction advances. Initially, a series of ions is observed starting at $m / z=201$ that formally corresponds to MTES and its oligomers (either linear or branched) with a " $\mathrm{SiO}(\mathrm{OEt})\left(\mathrm{CH}_{3}\right)$ " repeating unit $(\Delta m=104)$. Additional series of ions are also observed as the reaction proceeds starting at $m / z=439,573$, 707. The $m / z$ difference among these series of ions is $\Delta m=134$ which corresponds to a repeating " $\mathrm{Si}_{2} \mathrm{O}_{3}\left(\mathrm{CH}_{3}\right)_{2}$ " unit. The presence of each of these ions in the $\operatorname{ESI}(+)$ mass spectra is accompanied by additional species corresponding to formal addition of " $\mathrm{SiO}(\mathrm{OEt})\left(\mathrm{CH}_{3}\right)$ " units $(\Delta m=104$ addition), namely $m / z=439+n 104,573+n 104,707+n 104$. Table 2 shows plausible oligomer structures for the ESI detected ions.

The putative ladder-like oligomers shown in Table 2 are formed through intramolecular condensation to yield eightmembered $\mathrm{Si}_{4} \mathrm{O}_{4}$ cycles, however $\mathrm{Si}_{3} \mathrm{O}_{3}$ six-membered cycles

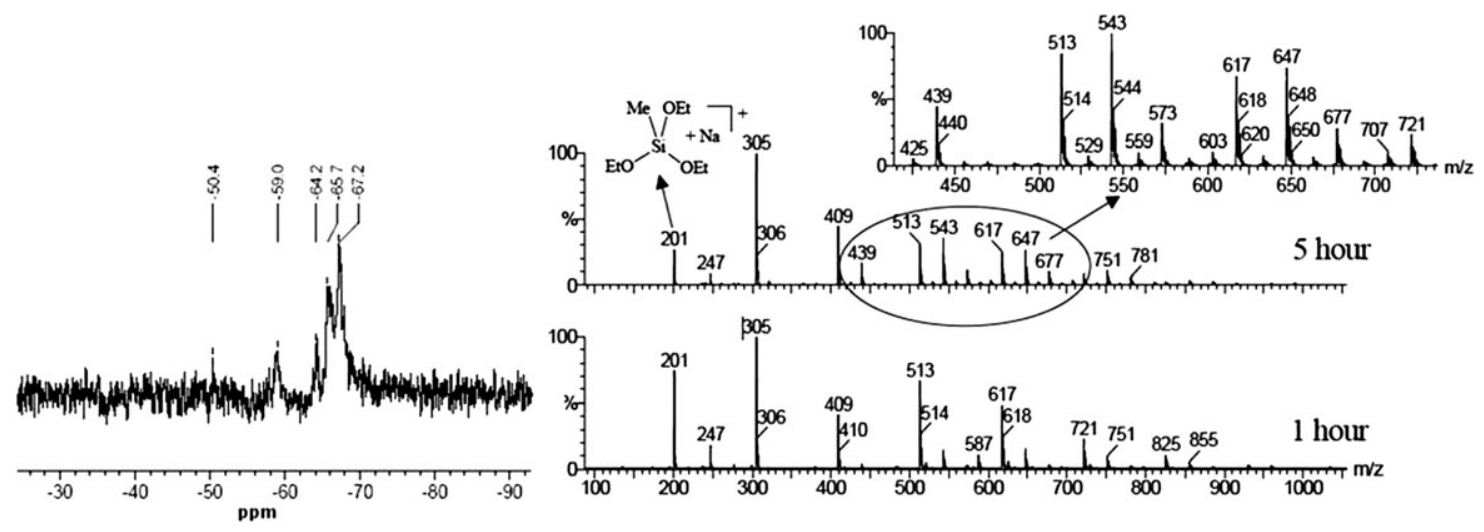

Fig. 5 (a) ${ }^{29} \mathrm{Si}\left\{{ }^{1} \mathrm{H}\right\}$ NMR spectrum after $c a .5 \mathrm{~h}$ and (b) $\mathrm{ESI}(+)$ mass spectra of hydrolyzed MDES under basic $(\mathrm{pH}=13)$ conditions. 
Table 2 Plausible molecular structures for the series of ions detected by ESI $(+)$-MS at $\mathrm{pH}=13$

\begin{tabular}{l}
\hline Proposed molecular structure \\
\hline
\end{tabular}<smiles>CCO[Si]12O[Si]3(OCC)O[Si]4(OCC)O[Si](OCC)(O1)O[Si]1(OCC)O[Si](OCC)(O2)O[Si](OCC)(O3)O[Si](OCC)(O4)O1</smiles>

439 (0), 543 (1), 647 (2), 751 (3), 855 (4), 959 (5)

$573(0), 677$ (1), $781(2), 885(3), 989$ (4)

$707(0), 811(1), 914(2)$

559,425

$469(0), 573(1), 677(2), 914(3)$

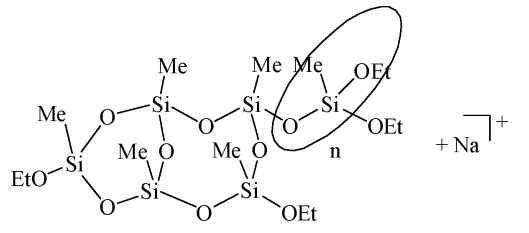

${ }^{a} n$ denotes the number of repeating " $\mathrm{Si}\left(\mathrm{CH}_{3}\right)(\mathrm{OEt})(\mathrm{O})$ " units.

are also likely formed (for instance in the T6 cage). Table 2 also includes the plausible structure for a series of oligomers starting at $m / z=469+n 104$ which bear a terminal six-membered cyclic motif. As can be inferred from Table 2 some of these ions are isomers of ladder-like oligomers (for example ions at $m / z=573$ may correspond to the ladder-like species shown in entries 3 or 6). In this sense, as the reaction advances, the species at higher mass-to-charge ratios are dominant and so the possibility of formation of different isomers precludes a reliable assignment on the basis of $\operatorname{ESI}(+)$-MS.

This temporal evolution suggests the growth of linear (or branched) MTES oligomers in the initial stages of the reaction and the formation of ladder-like oligomers as the reaction advances. This result is expected since the formation of the simplest ladder-like oligomer requires at least the presence of oligomers with four silicon atoms to promote intramolecular condensation. In this sense, it seems less likely that ladder-like oligomers are formed as a result of condensation of two smaller oligomers, i.e. condensation of two dimers. After $5 \mathrm{~h}$, minor signals in the $\mathrm{ESI}(+)$ mass spectra are observed at $m / z=425$ (assigned to the T6 cage) and $m / z=559$ (T8 cage, see Table 2).

\section{Conclusions}

The results obtained in this research have shown that ESI-MS, combined with ${ }^{1} \mathrm{H}$ and ${ }^{29} \mathrm{Si}\left\{{ }^{1} \mathrm{H}\right\}$ NMR spectroscopy, afford a unique tool for the detection of the oligomers formed through hydrolysis/condensation of organosilanes such as MDES. The ESI-MS experimental setup was previously analyzed in detail so as to determine the most suitable conditions that reflect the 
aqueous MDES speciation. The temporal evolution of MDES hydrolysis/condensation was monitored by ${ }^{29} \mathrm{Si}\left\{{ }^{1} \mathrm{H}\right\}$ NMR and ESI-MS techniques at $\mathrm{pH} \mathrm{1,6}$ and 13. In the cases of acid and neutral $\mathrm{pH}$, although ${ }^{1} \mathrm{H}$ and ${ }^{29} \mathrm{Si}\left\{{ }^{1} \mathrm{H}\right\}$ NMR results are in good agreement with those reported by other authors, they offer limited or ambiguous information on the molecular organization of the oligomers. In our study, the incorporation of ESI(+)-MS allows monitoring of temporal evolution of the oligomerization processes. For samples in basic medium, ${ }^{29} \mathrm{Si}\left\{{ }^{1} \mathrm{H}\right\}$ NMR results show $\mathrm{Si}-\mathrm{H}$ bond cleavage that leads to the formation of MTES species. ESI(+)-MS spectra indicate the appearance of several series of oligomers derived from MTES as the reaction advances.

With regard to the complementarity of both ESI-MS(+) and ${ }^{1} \mathrm{H},{ }^{29} \mathrm{Si}$ NMR analysis, some differences can be immediately inferred. The presence of very crowded ESI-MS spectra sharply contrast with the simplified ${ }^{29} \mathrm{Si}\left\{{ }^{1} \mathrm{H}\right\}$ NMR spectra of the reactive solution, showing that NMR analysis provides an inherently oversimplified picture due to the similarities of the silicon environments in the oligomers formed. Finally, this study also reveals that despite the oligomerization processes of MDES involving numerous elementary steps (consecutive hydrolysis and condensation and their reverse reactions) and the fact that each of them is difficult to investigate separately, the temporal evolution monitored by $\operatorname{ESI}(+)$ mass spectra unravel some trends on the intimate mechanism of oligomerization.

\section{Acknowledgements}

Financial support has been provided by Spanish Ministerio de Ciencia e Innovación (project MAT-2005-00541) and Bancaixa Foundation-Universitat Jaume I (P1-1B2007-47) project. J. Planelles-Aragó acknowledges personal financial support from a FPU Fellowship. The authors also thank the Servei Central D'Instrumentació Cientifica (SCIC) of the Universitat Jaume I for provision of NMR and MS facilities.

\section{References}

1 P. Innocenzi, G. Brusotin, M. Guglielmi and R. Bertani, Chem. Mater., 1999, 11, 1672; G. Schottner, Chem. Mater., 2001, 13, 3422.

2 C. Sanchez, B. Julian, P. Belleville and M. Popall, J. Mater. Chem., 2005, 15, 3559.

3 P. Gómez-Romero and C. Sanchez, in Functional Hybrid Materials, ed. P. Gómez-Romero and C. Sanchez, Wiley-VCH, Weinheim, 6th edn, 2003, ch. 1, pp. 1-10.

4 C. Sanchez, B. Lebeau, F. Chaput and J. P. Boilot, Adv. Mater., 2003, 15, 1969.

5 G. D. Soraru, D. D'Andrea, R. Campostrini and F. Babonneau, J. Mater. Chem., 1995, 5, 1363.

6 V. Gualandris, F. Babonneau, M. Janicke and B. F. Chmelka, J. Sol-Gel Sci. Technol., 1998, 12, 75.

7 R. Campostrini and S. Dirè, Proceedings EUROGEL'92. Advanced Materials and Processes by Sol-Gel Techniques, Colmar, 1992.

8 E. Cordoncillo, P. Escribano, B. Viana and C. Sanchez, J. Mater. Chem., 1998, 8, 507.

9 H.-H. Huang, R. H. Glaser and G. L. Wilkes, Inorganic and Organometallic Polymers, ACS Symp. Ser. 360; American Chemical Society, Washington DC, 1988.

10 H.-H. Huang, G. L. Wilkes and J. G. Carlson, Polymer, 1989, 30, 2001.
11 M. Yamane, S. Inoue and A. Yasumori, J. Non-Cryst. Solids, 1984, 63, 13.

12 R. A. Assink and B. D. Kay, Annu. Rev. Mater. Sci., 1991, 21, 491; N. Re, J. Non-Cryst. Solids, 1992, 142, 1.

13 D. H. Doughty, R. A. Assink and B. D. Kay, Silicon-Based Polymer Science: A Comprehensive Resource, American Chemical Society, Washington, DC, 1990.

14 H. Schmidt, H. Scholze and A. Kaiser, J. Non-Cryst. Solids, 1984, 63, 1 .

15 C. J. Brinker and G. W. Scherer, in Sol-Gel Science: The Physics and Chemistry of Sol-Gel Processing, Academic Press, San Diego, CA, 1st edn, 1989.

16 J. Livage, M. Henry and C. Sanchez, Prog. Solid State Chem., 1988, 18, 259.

17 M. A. Brook, in Silicon in Organic, Organometallic and Polymer Chemistry, Wiley Interscience, New York, 1st edn, 1999, ch. 7, pp. 171-185.

18 L. W. Kelts and N. J. Armstrong, Better Ceramics Through Chemistry III, Materials Research Society Symposium Proceedings, Pittsburgh, PA, 1988.

19 H. Chen, D. R. Bujalski and K. Su, J. Am. Soc. Mass Spectrom., $2005,16,524$.

20 W. E. Wallace, C. M. Guttman and J. M. Antonucci, J. Am. Soc. Mass Spectrom., 1999, 10, 224.

21 H. Chen and R. E. Tecklenburg, J. Am. Soc. Mass Spectrom., 2006, 17, 1437.

22 P. Eisenberg, R. Erra-Balsells, Y. Ishikawa, J. C. Lucas, H. Nonami and R. J. Williams, Macromolecules, 2002, 35, 1160.

23 W. E. Wallace, C. M. Guttman and J. M. Antonucci, Polymer, 2000, 41, 2219.

24 R. E. Tecklenburg, W. E. Wallace and H. Chen, Rapid Commun. Mass Spectrom., 2001, 15, 2176.

25 P. Bussian, F. Sobott, B. Brutschy, W. Schrader and F. Schüth, Angew. Chem., 2000, 112, 4065.

26 P. Bussian, F. Sobott, B. Brutschy, W. Schrader and F. Schüth, Angew. Chem., Int. Ed., 2000, 39, 3901.

27 S. A. Pelster, W. Schrader and F. Schüth, J. Am. Chem. Soc., 2006, 128, 4310.

28 S. A. Pelster, B. Weimann, B. B. Schaack, W. Schrader and F. Schüth, Angew. Chem., Int. Ed., 2007, 46, 6674.

29 K. Eggers, T. Eichner and J. Woenckhaus, Int. J. Mass Spectrom., 2005, 244, 72 .

30 X. M. Liu, E. P. Maziarz, D. J. Heiler and G. L. Grobe, J. Am. Soc. Mass Spectrom., 2003, 14, 195.

31 L. S. Santos and J. O. Metzger, Angew. Chem., Int. Ed., 2006, 45, 977.

32 P. Chen, Angew. Chem., Int. Ed., 2003, 42, 2832.

33 L. S. Santos and J. O. Metzger, Rapid Commun. Mass Spectrom., 2008, 22, 898.

34 S. A. Pelster, R. Kalamajka, W. Schrader and F. Schüth, Angew. Chem., Int. Ed., 2007, 46, 2299.

35 S. A. Pelster, F. Schüth and W. Schrader, Anal. Chem., 2007, 79, 6005.

36 J. S. Ritch and T. Chivers, Angew. Chem., Int. Ed., 2007, 46, 4610.

37 A. R. Bassindale, H. Chen, Z. Lin, I. A. Mackinnon, D. J. Parker, P. G. Taylor, Y. Yang, M. E. Light, P. N. Horton and M. B. Hursthouse, J. Organomet. Chem., 2004, 689, 3287.

38 A. R. Bassindale, D. J. Parker, P. G. Taylor, M. Pourry, P. G. Taylor, P. N. Horton and M. B. Hursthouse, Organometallics, 2004, 23, 4400.

39 P. Nemes, G. Schlosser and K. Vékey, J. Mass Spectrom., 2005, 40, 43.

40 F. Brunet, J. Non-Cryst. Solids, 1998, 231, 58

41 R. Tagore, H. Chen, R. H. Crabtree and G. W. Brudvig., J. Am. Chem. Soc., 2006, 128, 9457.

42 C. S. Parkhurst, W. F. Doyle, L. A. Silverman, S. Singh, M. P. Andersen, D. McClurg, G. E. Wnek and D. R. Uhlmann, Better Ceramics Through Chemistry, Materials Research Society Symposium Proceedings, Pittsburgh, PA, 1986.

43 H. Dong, M. Lee, R. D. Thomas, Z. Zhang, R. F. Reidy and D. W. Mueller, J. Sol-Gel Sci. Technol., 2003, 28, 5. 